\title{
Educación, formación humana y valores cooperativos: una propuesta de revitalización de las prácticas educativas brasileñas para el rescate del hombre social y fraterno
}

\author{
José Eduardo de Miranda \\ Doctor en Derecho \\ Andrea Corrêa Lima \\ Mestranda en Derecho-UNICESUMAR/Brasil
}

\begin{abstract}
El hombre se hace humano por la educación. La civilización humana progresa aceleradamente siempre por la acción formativa o educativa en la línea de búsqueda de valores humanos y sociales.
\end{abstract}

(Arizmendiarrieta, 1983, 80)

Sumario: Introducción. I. El trance entre la modernidad y la postmodernidad: ¿qué pasó con el valor del humano? II. El significado de la educación y los niveles de enseñanza escolar reconocidos por la Ley brasileña de Directrices y Bases de la Educación. III. Las finalidades de los procesos educacionales, de acuerdo con los niveles de educación en Brasil. IV ¿Cuál es el sentido de la formación humana? V. A título de conclusión: la inserción de los valores cooperativos en la práctica educativa como propuesta de rescate de la sociabilidad y de la fraternidad del hombre. VI. Referencias.

Resumen: La modernidad trajo en su esencia la posibilidad del hombre ejercer la plenitud de su capacidad racional, estableciendo un proceso evolutivo basado en la conformación del conocimiento y desarrollo de la ciencia. En un momento más reciente, en la postmodernidad, el hombre pierde el sentido de la sociabilidad y de la fraternidad, y pasa a vivir detenido en sus intereses personales, alejado de los demás y de las necesidades del mundo. Por ello, el trabajo tiene como objetivo el análisis de las finalidades de los niveles educacionales en Brasil, para que se pueda establecer una posibilidad de cambio de las prácticas educativas, a través de la utilización de los valores cooperativos en 
la formación educacional como supuesto de rescate del hombre fraterno y sociable.

Palabras clave: Educación. Valores Cooperativos. Formación humana.

Abstract: Modernity brought in its essence the possibility of man to exercise the fullness of his rational capacity, establishing an evolutionary process based on the formation of knowledge and development of science. In a more recent moment, in postmodernity, man loses the sense of sociability and fraternity, and happens to live in his personal interests, away from others and the needs of the world. Therefore, the objective of this study is to analyze the aims of educational levels in Brazil, so that a possibility can be established for changing educational practices, through the use of cooperative values in educational formation as an assumption of Rescue of fraternal and sociable man.

Keywords: Education. Cooperative values. Human training. 


\section{Introducción}

Mirándose hacia atrás, en la historia de la humanidad, se puede observar que la modernidad surge por vuelta del siglo XVIII, y trae la característica de ser un período contrario a las tradiciones de entonces, pues los hechos que se desarrollan a partir de este momento derrumban convenciones, cambian costumbres y creencias. Además, en virtud de las influencias filosóficas del Renacimiento y del lluminismo, revelase como una fase que marca la ética de la autonomía, por la cual se tiene la supresión de la concepción cosmológica y teocéntrica, que derroca la idea divina del origen de los reyes.

Por este camino, la modernidad germina la expectativa de emancipación del hombre, quitándole del agujero de su insignificancia delante del mundo, para ofrecerle la oportunidad de desvendar los límites de su racionalidad, transformándose en un sujeto pensante, libre del poder y de la fuerza de la religión; un hombre apto para ejercer su capacidad de entendimiento, sentimiento, y de relacionamiento con los demás.

La modernidad, por así decir, está asociada a la noción máxima de liberación y desarrollo humano, pues conforma un nuevo tipo de subjetividad que convierte el hombre en sujeto de conocimiento, de acción y de expansión. En la medida que pierde el sentido de finitud del mundo, y pasa a incrementar técnicas de exploración de nuevos continentes y promoción del mercantilismo, el hombre se hace víctima del desarrollo capitalista, "cuando surge la «nueva clase» de los comerciantes, hasta entonces menos preciados por la clase superior como meros «hombres del mercado» (mercaderes), villanos no habitantes del campo o tierra llana («burgueses»)» (Divar, 1985, p. 17).

Seguidamente, la herramienta sostenida por la mano humana, es sustituida por la máquina, y el mundo se depara con la Revolución Industrial, que automatiza los puestos de trabajo, y hunde la clase obrera en una terrible desventura material y moral (Aranzadi, 1976). El hombre, por consecuencia, vira rehén del capitalismo, sufriendo directamente los efectos producidos por el liberalismo económico. El paro, la desprotección social, la explotación incontrolada y la miseria acompañan las masas populares (Divar, 1985), que miran con incredulidad los mercenarios capitalistas emprendieren una procura sin precedentes por el costo productivo mínimo y el beneficio máximo.

En oposición a todas las dificultades que los hombres enfrentaban en esta época, y «frente al liberalismo económico, al socialismo marxista, y movimientos paralelos que sostienen como fórmula integradora el poder compensador, el Cooperativismo surge como reac- 
ción contra la barbarie instaurada por la Revolución Industrial»(Miranda, 2017, p. 55).

Conformado a partir de los preceptos estatutarios de los Probos Pioneros de Rochdale, y del ejercicio co-operativo articulado con base en experiencias anteriores, el Cooperativismo que nació en Rochdale se muestra como un sistema económico-social-moral «capaz de devolver la independencia y libertad al hombre, a través de la armónica conjunción que supone el trabajo común y la solidaridad para la búsqueda del bien estar social e incluso de la propia paz mundial» (Miranda, 2017, p. 55). Al mismo tiempo, y por «medio de las cooperativas, el Cooperativismo presenta una estructura organizada para realizar construcciones que, además de alcanzar los campos económicos y sociales, se encarga también del lado moral del individuo, mediante su formación humana» (Miranda, 2017, p. 98).

Hoy por hoy, cuando la modernidad se muestra una anciana, y las gentes se deparan con un momento llamado de postmodernidad, la humanidad se encuentra delante de una aparente revolución tecnológica, o una revolución silenciosa, que dejan los hombres cada vez más adictos a los aparatos virtuales, pasando a envolverse solamente con las cuestiones que les promueven intereses de orden personal. Ensimismados, los hombres renuncian los patrones que orientan la vida personal y social, y pierden la esencia de la referencia del valor del humano, pasando a establecer un existir de superficialidad, de apariencia y futilidad.

En razón del deseo imparable por la condición de bien estar personal, y valorizando solamente todo lo que es suyo, el individuo postmoderno sumerge dentro de sí, cerrase a los demás, poniéndose de espaldas a las necesidades de su entorno, de sus ajenos. Las preocupaciones de antaño, por lo social y por la realización de las necesidades del colectivo, ganan un colorido de formalidad, de previsión constitucional y legal, pero de distanciamiento subjetivo. La ética actual se muestra como la ética del individualismo, y hoy, más que en otros tiempos, "para el humano el bien general solamente le parece ser bien en cuanto posible comprensivo, por extensión, de su propio bien» (Divar, 1985, p. 15).

En este contexto, la educación brasileña pierde su aspecto transformador del individuo, y en las universidades, como en las escuelas, la enseñanza asume un papel protocolario, de cumplimento de planes pedagógicos que preponderan cuestiones relacionadas al contenido, evaluación de los exámenes y cuestiones formales de cumplimiento de indicadores.

Las entidades educadoras, por así decir, desprestigian la formación integral del sujeto, impidiéndole de hacerse un ser pensante, observa- 
dor de los fenómenos que se desarrollan en el mundo de la vida, y crítico de los sistemas socio-político-económicos que sostienen un absolutismo oculto tras las mascarillas de falsas democracias y de libertades aparentes.

Es por esto que juzgase apropiado discutir la educación, en Brasil, como una herramienta que debe proporcionar las condiciones de metamorfosis del hombre, para que pueda participar de las necesarias transformaciones de su comunidad, a través de un nítido e indiscutible ejercicio de ciudadanía plena. En este sentido, entendiese apropiado examinar la posibilidad de inserción de los valores cooperativos en la génesis de las prácticas educativas, para que se utilice el espíritu cooperativo en las acciones pedagógicas y formativas durante el proceso de formación de los individuos.

Para ello, con soporte del método deductivo de abordaje, y empleo de la investigación bibliográfica, utilizase el presente trabajo para sostener la perspectiva de cooperativizarse la enseñanza brasileña, para que se pueda revitalizar el valor del humano, y restablecer el sentido del hombre social, fraterno, y participativo en el medio en que vive.

\section{El trance entre la modernidad y la postmodernidad: ¿qué pasó con el valor del humano?}

La modernidad nace con el cierre de la Edad Media, en el momento en que el mundo mira a la caída del Imperio Romano del Oriente, y contempla la consolidación del Humanismo y del Renacimiento. A partir de entonces, el hombre pasa a hacer uso de su razón, dedicase al conocimiento técnico-científico y busca comprender la naturaleza y sus fenómenos. La cultura teocéntrica, que orientó el desarrollo de la humanidad hasta este periodo, es sustituida por el antropocentrismo, caracterizándose la contraposición al metafísico y al transcendental (Silva, 2004, 131). Pronto el hombre se abre para el mundo y para la ciencia, y su nueva razonabilidad le permite conquistar grandes descubiertas científicas, artísticas y literarias.

Por este camino, el hombre ultrapasa los límites de su campo visual y establece un proceso de exploración del mundo, más allá de sus fronteras originales. Contagiado por los ideales individualistas y liberales de los filósofos del siglo XVIII, el hombre sometiese a la libre concurrencia y a los efectos del dejar de hacer, dejar pasar. «Esto lleva al surgimiento del capitalismo como un fenómeno significativo, de absolutismo real y progreso económico, que se concentra en las manos de profusos burgueses, grandes industriales y ricos comerciantes que monopolizan 
los diversos tipos de empresas, inclusive la agrícola» (Miranda, 2017, p. 51).

En este escenario, el instinto de sociabilidad del hombre promueve la reunión de fuerzas colectivas para el suplante de condiciones de miseria física, moral y espiritual, enfrentadas en los albores de la Revolución Industrial. Mientras la máquina y la codicia maximizan el gano de los detentores del poder, el Cooperativismo nasce a través de la actuación de los Probos Pioneros de Rochdale como un movimiento que permite a «las gentes se aproximaren bajo valores y principios comunes, para eliminar todas las formas autoritarias de poder, y para permitir al propio hombre encontrar los medios necesarios a su completo desarrollo, tanto en el ámbito material, económico, social, personal y espiritual» (Miranda, 2012, p. 16).

La modernidad, a despecho de la sagacidad del capitalismo, y de los efectos de la Revolución Industrial, presentase, también, como un período de establecimiento de movimientos que promueven el reconocimiento de los derechos individuales y sociales, siempre marcados por el espíritu de solidaridad y fraternidad del hombre.

O projeto da modernidade formulado no século XVII pelos filósofos do lluminismo consiste num desenvolvimento implacável das ciências objetivas, das bases universalistas da moralidade e da lei e de uma arte autônoma consoante a lógica interna delas, constituindo ao mesmo tempo, porém, uma libertação dos potenciais cognitivos acumulados em decorrência de suas altas formas esotéricas e de sua utilização na práxis; isto é, na organização racional das condições de vida e das relações sociais. Os proponentes do lluminismo [...] cultivavam ainda a expectativa extravagante de que as artes e as ciências não somente aperfeiçoariam o controle das forças da natureza, como também a compreensão do ser e do mundo, o progresso moral, a justiça nas instituições sociais e até mesmo a felicidade humana. (Habermas, 2002, p. 77)

Sin embargo, con el pasar del tiempo el hombre se va distanciando de su raíz solidaria, co-operativa y participativa, y pasa a caminar por una ruta de aislamiento, donde se queda preocupado con cuestiones de orden personal, suyas. En la contemporaneidad, bienes y personas son factores efémeros y vanos para uno. La cultura del vacío, del tener por tener, del consumo insostenible, impulsa las manifestaciones inconsecuentes de placer y del poder. En cuanto las infinitas novedades ocupan diferentes espacios del mundo, las transformaciones en el seno de la existencia humana se desarrollan en velocidades indescriptibles, azuzando los individuos a querer más, a consumir sin límites, y pen- 
sar única y exclusivamente en sus deseos, en sus sentimientos y emociones. El hombre pasa a caminar como un ser de sus deseos, como un espectador de sus hechos, de su apariencia y de lo que siente que es, e imagina que tiene, pues es el hombre es un ser libre para hacer, para tener, y para creer (Colombo, 2012).

Nadie duda que las condiciones de vida del hombre moderno es distinta de las condiciones de vida de sus antepasados, o que se observa ya desde una perspectiva de libertad. Sin embargo, cuando mirada desde arriba, "pelos responsáveis pelo "curso da sociedade», pelos guardas do «bem comum», a liberdade do indivíduo devia preocupar o observador; ela é suspeita desde o início, pela simples imprevisibilidade de suas consequências, de ser de fato constante fonte de instabilidade, elemento de caos que se deve refrear para assegurar e manter a ordem» (Bauman, 1997, p. 12).

Tendemos a chamar de liberdade a ausência de restrições e limites obstrusivos e insidiosos. A maioria de nós, residentes do mundo moderno tardio ou pós-moderno, é, nesse sentido, livre de uma maneira que nossos ancestrais só podiam sonhar. E eles sonhavam; o desaparecimento milagroso de normas e limites era uma visão sedutora quando a vida era vivida com um temor diário de transgressão. Os pesadelos de nossos ancestrais de 50 a 100 anos atrás eram poderes sobre-humanos com suas demandas sobre-humanas. (Bauman, 2008, 61)

A despecho de las facilidades tecnológicas, o quizás por ellas, el hombre está esclavo del proceso de individualización. En cuanto libre para poner en práctica sus derechos, para ir y venir, para ser y estar, para hacer lo que quiera siempre que no moleste el ajeno, el hombre, detenido en un vínculo de dependencia de la tecnología, se hace un espécimen abducido por la fuerza de los aparatos electrónicos, centrado exclusivamente en él, e hundido en su excesiva preocupación existencial. Inmolado de la discontinuidad del evolucionismo socio-solidario, el hombre alejase de la afectuosidad de las relaciones interpersonales, pues las gentes están sumergidas en un mar de incertidumbres e incredulidades. Nadie más llama nadie por el teléfono, ya no se abraza, no se mira a los ojos, y tampoco se conjugan deseos comunes para la realización de objetivos colectivos.

En tiempos de una modernidad ultra moderna, que instaura un modelo llamado de postmodernidad, el hombre lleva una existencia automatizada, mira su razón ser incorporada por los comandos virtuales y pierde la ilusión del porvenir. El mañana es incierto, y lo que cuenta para el hombre postmoderno es el hoy, es lo que tiene ahora y todo lo 
que pueda mostrar externamente. La incertidumbre es una fuerza seccionadora de vínculos, un poder de individualización, que somete el hombre hacia un relacionamiento intrapersonal. La incertidumbre aleja las personas una de las demás, ahogando una noción colectiva de intereses comunes (Bauman, 2008).

Lejano del vínculo social, y distante de las cuestiones humanitarias, el hombre postmoderno se encuentra delante de una gran paradoja existencial: mientras conoce el más alto eslabón del desarrollo científico y tecnológico, es impotente de hacer lo que sea para cambiar situaciones de inestabilidad y de indignidad existencial que antaño preocupaban a todos.

Não é a esmagadora pressão de um ideal, com o qual não podem viver de acordo, que atormenta os homens e mulheres contemporâneos, mas a falta de ideais: a ausência das necessárias receitas eindeutig* para uma vida decente, dos pontos de orientação firmemente fixados e estáveis, do destino previsível para o itinerário da vida. A depressão —o sentimento da própria impotência, da incapacidade de atuar e particularmente da incapacidade de atuar de maneira racional-, para ser adequado às tarefas da vida - torna-se a malaise emblemática de nossos tempos modernos tardios ou pósmodernos. (Bauman, 2008, 60)

Con el avanzo de los tiempos, la facilitación del acceso a los productos de consumo, y con la transformación de los modelos sociales, el hombre postmoderno cerrase en sí mismo, desprecia los hechos del mundo, desecha la importancia de las gentes, y pone sus anhelos en el centro de la existencia. Del hombre político y social, de antiguamente, el hombre de hoy está un hombre apolítico, individual y preocupado únicamente con sus cuestiones personales. El trabajo, en otros tiempos desarrollado con el propósito de satisfacción de las necesidades básicas, comunes de un grupo, es utilizado para el deleite de placeres individuales, traducidos por la capacidad que uno tiene para demostrar una apariencia de ser y tener.

Aún peor, está el egoísmo del hombre postmoderno. Cuando no sufre solo, el hombre busca alguien para solidarizarse con su sufrimiento, y no para trabajar en el sentido de evitar un sufrimiento futuro, pues ya no tienen más los hombres una causa común, un deseo colectivo, o un valor que sea de todos, y para todos. El hombre postmoderno, víctima de su tiempo, y rehén de sus conquistas, es un ser solitario en el medio de la muchedumbre. Mártir del desprecio de la condición humana, y, necio de sí mismo, el hombre de hoy es incapaz de comprender el valor que las gentes poseen para su propia felicidad. 


\section{El significado de la educación y los niveles de enseñanza escolar reconocidos por la Ley brasileña de Directrices y Bases de la Educación}

Para comprenderse el significado de educación, es necesario rescatarse la máxima aristotélica de que el «hombre es un ser político, y está en su naturaleza vivir en sociedad» (Aristóteles, 1991, 212). Por ser político y sociable, el hombre no vive aislado y necesita de la convivencia con los demás.

Dentro de la perspectiva de coexistir con el ajeno, el hombre necesita conocerse a sí, conocer el mundo y aquellos que con él viven en el mundo. Bajo este aspecto, entendiese que la idea que refleja la condición política y sociable del hombre presupone la necesidad de implementación de acciones sistematizadas que viabilicen su existencia en la compañía de sus iguales. Es decir, para vivir con los demás, o para socializarse, el hombre necesita conocerse, echar un vistazo para fuera de sí, mirar al mundo y los otros que con él existen en el mundo.

La educación, pues, necesita ser confirmada como el elemento que permite al hombre la incesante acción de reconocimiento de sí, del mundo, y de los demás, pues se establece como un proceso vital e consciente de continua tomada de consciencia de si mesmo, para o homem continuar a aprofundar a própria personalidade, e procurar novos caminos de auto realização e de integração criativa e responsável na sociedade em que está inserido» (SCHIMITZ, 1993, 17). En cuanto un proceso que se desarrolla a lo largo de la vida, la educación permite el hombre mirar a su vuelta, tomar consciencia de sí mismo, y hallar los mejores caminos que le conduzcan a la realización personal, y a la conexión responsable con el medio de su inserción (Miranda, 2017).

Relevando-se a dualidade causa/efeito, nunca é demais dizer que a educação tem o condão de favorecer a adaptação do homem ao seu ambiente de vida, adequando-o ao convívio com os demais. Neste processo, pode-se contemplar o sentido da socialidade humana, e o caráter social da própria educação, pois é educando que tanto se promove o equilíbrio, como contrapesam eventuais conflitos que podem surgir entre os indivíduos, e entre estes com seu ambiente.

A despeito da orientação sobre a representatividade do termo educação, e da prática do educar, merece resgatar-se a orientação filosófica instituída por Hannah Arendt, para quem a educação se revela como o momento da vida em que os indivíduos decidem se amam suficientemente o mundo, para que possam assumir suas responsabilidades pelo mundo, e pelas gentes do mundo, salvando am- 
bos da iminente destruição que seria provocada pela ausência de uma renovação constante. (Miranda, 2017, p. 44)

De otra manera, la Ley brasileña de Directrices y Bases de la Educación, Ley 9.394, de 20 de diciembre de 1996, dispone, por su artículo $1 .^{\circ}$, que la educación no se conforma solamente en las actividades de clase, desarrolladas por profesores y alumnos, pero representa, también, infinitos procesos que se promueven en el transcurso de la vida de cada persona, derivados de la convivencia humana, de las relaciones de trabajo, del vínculo con instituciones de investigación, y mismo derivadas de la participación en movimientos sociales, manifestaciones culturales y en organizaciones de la sociedad civil (Brasil, 1996).

Mientras posibilite que el individuo vea más allá que sus intereses, la educación es un ejercicio permanente, que se ajusta a lo largo de toda la vida del hombre. Por ello, la Ley brasileña de Directrices y Bases de la Educación «impõe à família, à sociedade e ao Estado o dever pelos atos educativos, os quais devem ser inspirados em princípios de liberdade, e nos ideais de solidariedade humana, que possibilitem o pleno desenvolvimento do educando, preparando-o para o exercício da cidadania, e qualificando-o para o mercado de trabalho» (Miranda, 2017, p. 45).

La educación, por tanto, es un fenómeno imparable, y está presente en la vida del hombre durante toda su existencia. Se procesa tanto en el ámbito de las escuelas, de las universidades o instituciones científicas, como en el escenario cualquier en donde se encuentre el hombre: educase en la escuela, educase en todos los sitios (Freire, 1997).

Por esto, hay que entenderse que la enseñanza escolar se establece dentro de un orden cronológico de edad y capacidad, que permita al educando sintonizarse con el mundo, para pueda cumplir con su papel delante del mundo (Miranda, 2017, 46). En este sentido, el artículo 21 de la Ley brasileña de Directrices y Bases de la Educación determina que la enseñanza escolar es composta por los niveles llamados de educación básica, que es constituida por la educación infantil, la enseñanza fundamental y media (correspondiente a secundarias y al bachillerato), y la enseñanza superior (equivalente a la carrera universitaria).

\section{Las finalidades de los procesos educacionales, de acuerdo con los niveles de educación en Brasil}

Teniendo en cuenta que la educación es el fenómeno que se establece a lo largo de la existencia del hombre, y se desarrolla en distintos 
sectores, es importante observarse que en el ámbito de la enseñanza, o de la educación escolar, la finalidad es trazada para el éxito de la formación de un sujeto capaz de relacionarse con el mundo, con las gentes del mundo, y de participar de los procesos de transformación que se constituyen en el seno de la sociedad en donde se encuentra inserido. Es por esto que en Brasil suélese hablar en educación para el ejercicio de la ciudadanía, o educación para formar individuos integrados y actuantes en su medio.

De esta manera, y de acuerdo con la Ley brasileña de Directrices y Bases de la Educación, la educación escolar es la que se conforma en el ámbito de las instituciones educacionales (escuelas y universidades), sigue una organización formativa que procura ajustarse en razón etaria y de capacidad del alumno, para que, en la medida que crece en términos de edad, progrese como persona, como ciudadano.

A par de ello, la Ley brasileña de Directrices y Bases de la Educación determina que en la primera etapa de la educación escolar básica, la educación infantil, la escuela es un agente que actúa en coparticipación con la familia y con la comunidad, trabajando para el desarrollo de los aspectos psicológicos, intelectuales y sociales del niño (Brasil, 1996). A lo largo de sus cinco primeros años de vida, el sujeto debe ser puesto en contacto con el sentido de los valores humanos y sociales, para que comprenda el significado del respecto a los límites de la libertad, y a los derechos de los demás (Miranda, 2017).

Después, en el momento denominado segunda etapa de la educación escolar básica, o enseñanza fundamental, el niño necesita ser preparado para desarrollar su capacidad de aprendizaje, dominar la lectura, la escrita y los cálculos; comprender el ambiente natural y social, el sistema político, la importancia y aplicabilidad de la tecnología, de las artes y de los valores sociales; fortalecer sus vínculos con la familia; despertar el sentimiento de solidaridad humana; y conocer el sentido de la tolerancia.

Art. 32. O ensino fundamental obrigatório, com duração de 9 (nove) anos, gratuito na escola pública, iniciando-se aos 6 (seis) anos de idade, terá por objetivo a formação básica do cidadão, mediante: - o desenvolvimento da capacidade de aprender, tendo como meios básicos o pleno domínio da leitura, da escrita e do cálculo;

II. a compreensão do ambiente natural e social, do sistema político, da tecnologia, das artes e dos valores em que se fundamenta a sociedade;

III. o desenvolvimento da capacidade de aprendizagem, tendo em vista a aquisição de conhecimentos e habilidades e a formação de atitudes e valores; 
IV. o fortalecimento dos vínculos de família, dos laços de solidariedade humana e de tolerância recíproca em que se assenta a vida social. (Brasil, 1996)

Ya con una edad más próxima de la adolescencia, el joven educando ingresa en la última etapa de la educación básica, llamada enseñanza media, para fortalecer contenidos, dominar informaciones de asignaturas diversas, y ser capacitado para ser una persona flexible, ética, reflexiva y crítica.

Art. 35. O ensino médio, etapa final da educação básica, com duração mínima de três anos, terá como finalidades:

I. a consolidação e o aprofundamento dos conhecimentos adquiridos no ensino fundamental, possibilitando o prosseguimento de estudos;

II. a preparação básica para o trabalho e a cidadania do educando, para continuar aprendendo, de modo a ser capaz de se adaptar com flexibilidade a novas condições de ocupação ou aperfeiçoamento posteriores;

III. o aprimoramento do educando como pessoa humana, incluindo a formação ética e o desenvolvimento da autonomia intelectual e do pensamento crítico;

IV. a compreensão dos fundamentos científico-tecnológicos dos processos produtivos, relacionando a teoria com a prática, no ensino de cada disciplina. (Brasil, 1996)

Finalmente, cuando se encuentra en la universidad, o como suele decirse en Brasil, cumpliendo con la Facultad en la educación superior, la formación educativa canaliza el ejercicio del aprendizaje para el desarrollo de competencias y habilidades profesionales, sin perder el sentido de seguir articulando medios de evolución y progreso personal del estudiante. La Ley es especifica en el sentido de que se debería ofrecer contenidos y fenómenos específicos, adscritos a diferentes áreas de conocimiento, asociados al desarrollo de posturas y actitudes comportamentales propias al avance de la condición humana del alumno, haciéndole nutrir un permanente sentimiento de respeto y preocupación en relación a los demás, y en relación al medio en que se encuentra inserido.

Es decir, la formación universitaria, de acuerdo con la legislación y los principios educacionales en Brasil, es la etapa de la enseñanza escolar utilizada para solidificar la sensación de integración del alumno con su sociedad, haciéndole comprender que es parte de un medio, para que entienda el sentido del medio para su desarrollo personal y profe- 
sional, la importancia de los demás, y el alcance de su responsabilidad por los demás y por el mundo (Miranda, 2017).

La universidad es el punto neurálgico de la maduración de la personalidad del estudiante, pues, es a través del proceso formativo en este nivel educacional que el alumno vigoriza su autonomía e independencia intelectual y personal, haciéndose responsable por sus actos y por su propio futuro. Hay, por tanto, un equilibrio de los ejes formativos en la universidad, porque en la misma proporción que el estudiante necesita hacerse profesional, precisa crecer como persona humana, pues de nada le vale ser un técnico ajeno al mundo y a los demás (Miranda, 2017).

Art. 43. A educação superior tem por finalidade:

I. estimular a criação cultural e o desenvolvimento do espírito científico e do pensamento reflexivo;

II. formar diplomados nas diferentes áreas de conhecimento, aptos para a inserção em setores profissionais e para a participação no desenvolvimento da sociedade brasileira, e colaborar na sua formação contínua;

III. incentivar o trabalho de pesquisa e investigação científica, visando o desenvolvimento da ciência e da tecnologia e da criação e difusão da cultura, e, desse modo, desenvolver o entendimento do homem e do meio em que vive;

IV. promover a divulgação de conhecimentos culturais, científicos e técnicos que constituem patrimônio da humanidade e comunicar o saber através do ensino, de publicações ou de outras formas de comunicação;

V. suscitar o desejo permanente de aperfeiçoamento cultural e profissional e possibilitar a correspondente concretização, integrando os conhecimentos que vão sendo adquiridos numa estrutura intelectual sistematizadora do conhecimento de cada geração;

VI. estimular o conhecimento dos problemas do mundo presente, em particular os nacionais e regionais, prestar serviços especializados à comunidade e estabelecer com esta uma relação de reciprocidade;

VII. promover a extensão, aberta à participação da população, visando à difusão das conquistas e benefícios resultantes da criação cultural e da pesquisa científica e tecnológica geradas na instituição.

VIII. atuar em favor da universalização e do aprimoramento da educação básica, mediante a formação e a capacitação de profissionais, a realização de pesquisas pedagógicas e o desenvolvimento de atividades de extensão que aproximem os dois níveis escolares. (Brasil, 1996) 
Ocurre que todo el cambio intrapersonal sufrido por el hombre durante el trance entre la modernidad y la postmodernidad, posiblemente esté conectado directamente con los patrones educacionales modernos, desarrollados a lo largo de la propia modernidad. E esto, lejos de una suposición pasional, resulta del carácter técnico-científico instaurado por la modernidad, que impone al hombre la impulsión por el conocimiento. Razón de ello, los procesos educacionales y los métodos de enseñanza se preocuparon demasiadamente por las cuestiones cognitivas de los sujetos, poniendo sus sentimientos y emociones en un plan secundario, de modo que aprender responde al sinónimo de dominar las ciencias y la tecnología, y la sabiduría es la posibilidad que uno tiene de generar hechos cuantitativos.

Hay, por así decir, un preeminente quehacer concentrado en el material, que genera un ser mecánico, que responde a los problemas sin evaluar su causa, pensando simplemente en su resultado y solución. Como consecuencia, el hombre expresa su racionalidad de forma instrumental, enredándose mecánica y materialmente con las distintas formas de dominación (Prestes, 1997, p. 84), de ostentación y de realización de sus intereses personales.

\section{IV. ¿Cuál es el sentido de la formación humana?}

Desde que se tiene noticia de su surgimiento en la Tierra, el hombre nunca estuvo solo, pues es un ser gregario, que vive en comunidad. Social y político, como dijo Aristóteles (1991, 212), el hombre no está aislado en el tiempo y en el espacio. Por ello, las instituciones educacionales existen para colaborar con la formación sistémica de los individuos, permitiéndoles comprender que todo su aprendizaje hace parte de una vivencia humana, y sus conocimientos son destinados específicamente a los hombres.

Es cierto que en el apogeo de siglo XXI la humanidad necesita de profesionales capacitados para el ejercicio de sus actividades técnicas, pero no es diferente que la humanidad carece de profesionales técnicos que sean capaces de ponerse en la condición de uno que está en situación desfavorable, que padece de amarguras sociales, o mismo personales, que le impiden empezar una jornada que termine con su propia realización.

La formación humana no es una formación que sustituye la formación técnica, pero es la formación técnica-profesional-científica que permite a los sujetos del conocimiento entendieren que no están solo en el mundo, y que sus actitudes pueden afectar la vida, la felicidad y la libertad ajena. 
Por lo demás, la educación necesita sembrar el sentimiento de obligación intervencionista, haciendo con que el estudiante, sea en la época formativa, sea como profesional, debe participar de su comunidad, identificando demandas y colaborando con sus respectivas soluciones, después de descubrir sus causas. "O ato de formar transcende o singular preparo para o exercício de uma profissão de forma individual, e preconiza um envolvimento global com o mundo em que o profissional se encontra, participando de suas demandas, e colaborando coma sua transformação» (Miranda, 2017, p. 152).

Outro saber de que não posso duvidar um momento sequer na minha prática educativo-crítica é o de que, como experiência especificamente humana, a educação é uma forma de intervenção no mundo. Intervenção que além do conhecimento dos conteúdos bem ou mal ensinados e/ou aprendidos implica tanto esforço de reprodução da ideologia dominante quanto o seu desmascaramento. (Freire, 1997, p. 110)

El sentido de la formación humana es observado cuando una entidad educacional trata la «educação como um instrumento de mudança intrínseco ao desenvolvimento de um processo humano e social pelo qual o ser o humano, em constante transformação e integração com seu meio, constrói o mundo e participa da história. Na medida em que o tira de dentro de si, ele entra no mundo, fazendo parte efetiva dele, contribuindo com as mudanças que se fizerem necessárias» (Miranda, 2017, p. 59-60).

\section{A título de conclusión: la inserción de los valores cooperativos en la práctica educativa como propuesta de rescate de la sociabilidad y de la fraternidad del hombre}

Primeramente, es necesario reeditar que el Cooperativismo surge durante las amarguras de la Revolución Industrial, a través de la creación de la Sociedad Cooperativa de los Probos Pioneros de Rochdale. Formateado bajo principios definidos para su especificidad de ejercicio socio-económico, no usurero, el Cooperativismo conformase en el mundo como siendo la pura esencia de la cooperación libre, que determina la abolición de las estrategias egocentristas, concentradoras de fuerzas particulares para la satisfacción de aspiraciones personales, de forma reducida al interese económico y material de unos pocos. 
[...] el Cooperativismo es la cooperación formalizada bajo unos principios que sostienen una estructura organizada para la satisfacción de necesidades diversificadas, una estructura que se desarrolla a partir de la puesta en práctica de valores que permiten el desarrollo de la acción humana dirigida a la búsqueda de un bien que es común para todo un sector fragilizado: el bienestar del hombre, el bien social, económico y sobre todo, espiritual, puesto que el hombre cooperativo solo está bien, cuando sus semejantes también lo están. (Miranda, 2012, 16)

En este sentido, la Alianza Cooperativa Internacional, durante el Congreso de Manchester, en el año de 1995, emite la Declaración sobre la Identidad Cooperativa, enunciando los valores del Cooperativismo que «reflejan los ideales trazados por los precursores, a través de la iniciativas que han apuntado a una cooperación que, además de solucionar las necesidades materiales del hombre, se ha preocupado de colaborar con su transformación moral» (Miranda, 2012, 62).

De acuerdo con la Declaración sobre la Identidad Cooperativa, los valores cooperativos son divididos en dos grupos: uno llamado de valores cooperativos fundamentales, que es compuesto por la autoayuda, la autorresponsabilidad, la democracia, la igualdad, la equidad y la solidaridad; y otro, denominado de valores éticos, integrados por la honestidad, la transparencia, la responsabilidad y la vocación social $(\mathrm{ACl}, 1996,86)$. Mientras los primeros se muestren relacionados directamente con la estructura organizativa de las sociedades cooperativas, y sirven para conferir uniformidad para el ejercicio del Cooperativismo, los segundos están conectados con la figura personal de los miembros y de los trabajadores de la cooperativa, y sirven para exhibir el aspecto moral de la cooperatividad.

Como un todo, los valores cooperativos ponen en evidencia el espíritu del Cooperativismo, que sostiene la preocupación primera por el hombre, y demarca que su bienestar social, económico y espiritual es la clave central del suceso y solidez del movimiento cooperativo mundial.

Es así que la principal tarea de la entidad cooperativa es sembrar el entendimiento entre los ciudadanos; ubicar su ejercicio empresarial en el sentido más ventajoso al bien común; favorecer la solución de las dificultades, permitiendo nuevos caminos que conduzcan a los individuos al encuentro de la prosperidad; y participar del desarrollo educativo del ser humano, de forma que éste se vea involucrado en una existencia basada en la valor cooperativa. (Miranda y Miranda, 2015, 31) 
Teniendo en cuenta los efectos que el trance entre modernidad y postmodernidad provocaron en el hombre de hoy, haciéndole un ser individualista, detenido en sí mismo, alejado de sus iguales y ciego a las realidades de su entorno, olvidándose de la importancia que los demás tienen a su propia vida, es hora de repensarse la forma por la cual el hombre postmoderno es educado y preparado para la vida, poniéndose en relieve la importancia de optimizarse un ejercicio axiológico en el proceso educacional.

En este sentido, considerando que la regulación de la enseñanza brasileña establece directrices curriculares para el desarrollo de los distintos niveles educativos (Brasil, 1996), se hace tarde el momento de los expertos actuaren en el sentido de revitalización de los currículos escolares de Brasil, para que se establezca una práctica educacional que viabilice el rescate del hombre fraterno y social.

Mismo que la Ley brasileña de Directrices y Bases de la Educación evidencie una preocupación por la formación de un individuo más humano, engajado en su medio y participativo de los procesos de mudanza y transformación social (Brasil, 1996), esto parece olvidado en el contexto educativo brasileño, pues en las escuelas, y mismo en las universidades, la práctica educativa se ajusta únicamente bajo un patrón cuantitativo, de informaciones repasadas al alumno. Al recurrirse por las escuelas y universidades brasileñas se puede detectar que el objetivo educativo es sencillo y limitado a la promoción de un conocimiento descriptivo y sistemático de conceptos y normas formales.

Día tras día las escuelas y las universidades trabajan con la transmisión de contenido, y desprecian la integración axiológica en el seno educacional. El alumno se desarrolla dentro de una dinámica de detener información, pero sin condiciones de asociar la información que detiene con los hechos de la existencia. El alumno aprende a dominar las tecnologías, pero se aleja del dominio del sentimiento necesario al desarrollo de relaciones interpersonales, y al uso de un juicio crítico respecto al cierto, al equivocado.

Hay que hacerse algo, pues las escuelas y las universidades no son solamente un lugar donde circula informaciones, pero son sitios que promueven influencia en la formación de la personalidad de los alumnos, determinando el rumbo de sus propias historias profesionales y personales. Por ello, es necesario mirarse al núcleo de los currículos escolares y académicos, para que se perciba que su contenido prevé la humanización de la enseñanza como palanca de integración del individuo al medio, respetando a los demás y haciéndose parte del contexto de su existencia. 
Es en este sentido que se entiende oportuno que los currículos optimicen la utilización de los valores cooperativos en las prácticas educacionales, para que las escuelas y las universidades adopten en la práctica un ejercicio axiológico indispensable para la complementación de la formación técnico-científico con valores que aportaran un aspecto de moralidad instructiva, llevando el hombre más allá de las fronteras de las informaciones y de los aparatos virtuales, re-significando la ética de su existencia.

A ideia que defendemos é bem mais concreta: trata-se apenas de criar em cada pessoa um método de compreensão e de reciprocidade. Que cada um, sem abandonar seu ponto de vista, e sem procurar suprimir suas crenças e seus sentimentos, que fazem dele um homem de carne e osso, vinculado a uma porção bem delimitada e bem viva do universo, aprenda a se situar no conjunto dos outros homens. Que cada um se agarre assim à sua própria perspectiva, como a única que conhece desde dentro, mas compreenda sobretudo que a verdade, em todas as coisas, nunca se encontra pronta, mas é elaborada penosamente, graças à própria coordenação dessas perspectivas. (Piaget, 1931b/1998, p. 85)

En la búsqueda por una pedagogía que logre la humanización de los procesos educativos, los valores cooperativos éticos y fundamentales presentan un paradigma adecuado para ser utilizado por las prácticas educacionales en todos los niveles de la enseñanza escolar, pues ya dejaron evidente que contribuyen con la sembradura de valores sociales y morales de una sociedad que necesita de un hombre más humano, social y fraterno (Miranda, 2012).

Además, la inserción de los valores cooperativos en las prácticas educativas permite el contacto directo e imparable de los alumnos con la esencia de la cooperación, o que se torna indispensable para el desarrollo del respeto mutuo y del sentimiento de igualdad, sostenidos por la noción máxima de justicia.

La experiencia de los hechos de los Probos Pioneros de Rochdale y la realidad que acompaño el hombre a lo largo de su propia historia permite confirmar que el «hombre formado bajo la filosofía de los valores es un hombre co-operativo, es el hombre que se preocupa con su bienestar, y con el bienestar del prójimo que comparte con él el mismo entorno» (Miranda, 2012, p. 147).

Por esto, se tiene como viable que las prácticas educativas brasileñas adopten los valores cooperativos éticos y fundamentales como técnica de rescate y manutención del hombre necesario para el mundo hoy, un hombre afectuoso, dotado de predicados morales y sociales 
fundamentales al fortalecimiento de su medio. E esto se muestra importante, pues, siendo la educación un proceso vital de tomada constante de la consciencia por parte de cada uno, las personas serán constantemente multiplicadoras de los valores cooperativos, diseminando en el seno de su entorno la tenacidad axiológica de la cooperatividad.

A partir desse direcionamento, não se pode desprezar que na medida em que somos educandos, também estamos educadores, e nossa relação com os demais perfaz uma prática educativa constante, em que ao mesmo tempo se educa e se é educado, pois precisamos constantemente olhar para fora, para entender o mundo, para respeitar os demais.

No dia a dia, então, devemos agir com mais cautela, pensando nas palavras que são ditas aos outros, sendo mais tolerante e procurando compreender a dificuldade de cada um.

Olhar para fora de si não é esbanjar conhecimento ou enaltecer sabedoria...

Olhar para fora de si é desenvolver a capacidade de entender as diferenças que existem no mundo, para que se possa, cada vez mais, compreender que a plenitude da igualdade repousa no respeito à diferença de cada um. (Miranda, 2017, 45)

La educación basada en los valores cooperativos, convergente con la Ley brasileña de Directrices y Bases de la Educación, quitará el hombre postmoderno de su agujero intrapersonal, permitiéndole mirar que «el mundo es un gran palco donde ensenan actores diferentes, que poseen necesidades que les son propias, pero que tienen en común el deseo de realizaren sueños, de ser felices y transformarse en alguien en sus vidas» (Miranda, 2017, 46).

En todo su texto, Ley brasileña de Directrices y Bases de la Educación deja claro la necesidad de que los niveles educacionales desarrollen la calidad humana de los estudiantes, poniéndoles en contacto permanente con las personas, con la sociedad y con el medio, colaborando para las transformaciones pertinentes a cada época, durante su vida.

Asimismo, no se puede olvidar que la educación permite uno decidir su amor por el próximo y por el mundo, para que asuma su responsabilidad por ambos, actuando, siempre, para salvaguardarlos de los posibles cambios y de la inevitables ruinas que ocurrirían en un mundo de intereses únicamente material (Arendt, 1957), en donde los hombres pasasen su vida preocupados con lo suyo y relacionándose únicamente con los aparatos virtuales.

La educación debe suplantar la enseñanza únicamente técnica, pues es solamente a través de la adquisición de valores inmateria- 
les que los hombres pueden tornarse hombres de verdad, dotados de una capacidad laboral para el ejercicio de cualquier oficio técnico científico, no despegado de su capacidad emocional, indispensable a su condición fraterna y sociable, imprescindible para su existencia en sociedad.

Por ello, la autoayuda, la autorresponsabilidad, la democracia, la igualdad, la equidad, la solidaridad, la honestidad, la transparencia, la responsabilidad y la vocación social deben ser trabajados en el orden educacional para que los estudiantes les lleven en su alma, y sean capaz de compartir su sentido con aquellos que dividen el mundo consigo, para que juntos conformen una cadena humana que rescate el sentido de la fraternidad y la importancia de la sociabilidad del hombre.

No se puede olvidar, jamás, que un hombre que tiene valor es el hombre que reconoce el valor que los demás tienen para él y para el mundo, es el hombre que identifica los problemas del mundo y trabaja en pro de su eliminación. Es así que la educación no puede alejarse de su propósito de formar hombres, y no exclusivamente llenar personas de conocimientos técnicos, transformando la gente en autómata de su propia existencia y de la existencia de los demás. Esto se hará posible a través del empleo de los valores cooperativos éticos y fundamentales, los cuales reposan reconocidos como elementos indisociables de la cooperación libre, solidaria y justa.

\section{Referencias}

Arendt, Hanahn. 1957. A crise da educação. Disponible en http:// escoladeredes.net/group/bibliotecahannaharendt (acceso en 28/jun/2017).

Aristóteles. 1991. Ética a Nicômaco. Poética. Seleção de textos de José Américo Motta.

Pessanha. Nova Cultural: São Paulo.

Alianza CoOperativa InternaCional. 1996. «Declaración de la Alianza Cooperativa Internacional sobre la Identidad Cooperativa aprobada en Manchester» In Anuario de Estudios Cooperativo. Bilbao: Universidad de Deusto.

AlEXY, Robert. 2003. "Tres escritos sobre los derechos fundamentales y la teoría de los principios». In Serie de teoría jurídica y filosofía del Direito. N 28. Universidad de Externado de Colombia: Bogotá.

AranzadI, Dionisio. 1976. Cooperativsimo industrial como sistema, empresa y experiencia. Universidad de Deusto: Bilbao.

ArizmendiarRIETA, José María. 1983. Pensamientos. Caja laboral Popular: Estella.

DIVAR, Javier. 1985. La alternativa cooperativa: una respuesta ante la crisis. Barcelona: Ceac. 
BAuman, Zygmunt. 1997. Ética pós-moderna. Tradução João Rezende Costa. Paulus: São Paulo.

- 2008. A sociedade individualizada: vidas contadas e histórias vividas. Tradução José Gradei. Jorge Zahar Ed: Rio de Janeiro.

-. 2010. Vida a crédito: conversas com Citlali Rovirosa-Madrazo. Tradução José Gradei. Jorge Zahar Ed: Rio de Janeiro.

BrasIL. 1996. Lei 9.394, e 20 de dezembro de 1996. Disponible en http://www. planalto.gov.br/ccivil_03/leis/L9394.htm (acceso en 28/jun/2017).

Colombo, Maristela. 2012. In Modernidade: a construção do sujeito contemporâneo e a sociedade de consumo. Revista brasileira de psicodrama. vol. 20, no. 1. São Paulo.

DworkIN, Ronald. 2002. Levando os Direitos a sério. Tradução de Nelson Boeira. São Paulo: Martins Fontes.

Espíndola, Ruy Samuel. 2002. Conceito de princípios constitucionais. 2 ed. São Paulo: RT.

FreIRE, Paulo. 1997.Pedagogia da autonomia: saberes necessários à prática educativa. Paz e Terra: Rio de Janeiro.

HABERMAS, Jürgen. 2002. O discurso filosófico da modernidade. Martins Fontes: São Paulo.

MiRANDA, José Eduardo. 2017. Filosofía cooperativa: análisis del proceso de conformación del Cooperativismo. Lisboa: Juruá.

—. 2017. MAL DITA FACUL... Tô dentro, e agora? Curitiba: Prismas.

- 2012. De la crisis de identidad al rescate de la génesis del Cooperativismo. Madrid: Dykinson.

MIRANDA, José Eduardo de y MIRANDA, Victória Corrêa Lima de. 2015. «La perspectiva tridimensional de la calidad del cooperado en relación a la sociedad cooperativa: del rescate de la idea de un hombre cooperativo hacia la preservación de la identidad cooperativa» In Deusto estudios cooperativos. Universidad de Deusto: Bibao.

PIAGET, Jean. 1998. «Introdução Psicológica à Educação Internacional» In PIAGET. Jean. Sobre a Pedagogia: textos inéditos. Casa do Psicólogo: São Paulo.

Prestes, Nadja H. 1997. "Metafísica da subjetividade na educação: as dificuldades do desvencilhamento» In Educação e Realidade. Porto Alegre, 22(1) 81-94, jan/jun.

Schimitz, Egídio Francisco.1993. Fundamentos da didática. Unisinos: São Leopoldo.

SILVA, Maria Vieira. 2001. «O declínio dos paradigmas da modernidade e as experiências pós-modernas: tudo que é sólido desmancha no ar?». Educação e filosofia. V. 18 (35/36) 126/144. Jan/dez. 